\title{
Assessment of motor recovery and MRI correlates in a porcine spinal cord injury model
}

\author{
Igor Šulla ${ }^{1}$, Ladislav Bačiak ${ }^{2}$, Ivo Juránek ${ }^{3}$ Tatiana Cicholesová ${ }^{4}$, Martin Boldižár ${ }^{5}$, \\ Vladimir Balik ${ }^{6}$, Nadežda Lukáčová ${ }^{7}$
}

${ }^{1}$ University of Veterinary Medicine and Pharmacy, Department of Anatomy, Histology and Physiology, Kosice, Slovakia

${ }^{2}$ Slovak Technical University, Faculty of Chemical and Food Technology, Department of NMR Spectroscopy and Mass Spectrometry, Institute of Analytical Chemistry, Bratislava, Slovakia

${ }^{3}$ Slovak Academy of Sciences, Institute of Experimental Pharmacology and Toxicology, Bratislava, Slovakia

${ }^{4}$ University Hospital of L. Pasteur, Department of Physiotherapy, Kosice, Slovakia

${ }^{5}$ University of Veterinary Medicine and Pharmacy, Clinic for Horses, Kosice, Slovakia

${ }^{6}$ University Hospital, Department of Neurosurgery, Olomouc, Czech Republic

${ }^{7}$ Slovak Academy of Sciences, Institute of Neurobiology, Kosice, Slovakia

\section{Received December 24, 2013 \\ Accepted July 23, 2014}

\begin{abstract}
The study concentrated on behavioral and magnetic resonance imaging (MRI) characteristics in a porcine spinal cord injury model. Six adult minipigs weighing $32-35 \mathrm{~kg}$ were narcotized by thiopental, intubated, and placed on a volume-cycled ventilator. Anaesthesia was maintained by $1.5 \%$ sevoflurane with oxygen. Following location of the $1^{\text {st }}$ lumbar vertebra animals were fastened in an immobilization frame. The spinal cord, exposed through a laminectomy, was compressed by a $5 \mathrm{~mm}$ thick circular rod with a peak force of $0.8 \mathrm{~kg}$ at a velocity of $3 \mathrm{~cm} \cdot \mathrm{s}^{-1}$. The next day the minipigs were paraplegic but improved rapidly to paraparesis. On the $12^{\text {th }}$ postoperative day they were euthanasied. Neural tissue changes were evaluated by post mortem MRI, which showed damage to the spinal cord white and/or gray matter in the epicentre of compression with longitudinal spreading over one segment cranially and caudally. Statistical analyses performed by Spearman's rho test revealed positive correlations between damaged areas and the whole area of the spinal cord white/gray matter $\left(P=0.047 ; \mathrm{r}_{\mathrm{s}}=0.742\right)$ and $\left(P=0.002 ; \mathrm{r}_{\mathrm{s}}=\right.$ $0.943)$, respectively. The study confirmed the reliability and reproducibility of the utilised model of spinal cord trauma. The structural changes in the epicentre of injury did not impede the rapid but incomplete recovery of motor functions.
\end{abstract}

Experimental model, minipig, spinal trauma, outcome

Spinal cord injuries (SCI) with their life-long consequences belong to the most devastating pathological conditions. Their severity has stimulated both basic researchers and healthcare professionals for decades to study the pathophysiological processes initiated by the traumatic event and their sequelae with the goal of developing effective treatment. Animal experiments are essential to these efforts. Recent data demonstrate that therapeutic measures producing positive results in small laboratory animals are not effective in humans (Kwon et al. 2010). These facts inspired the authors to study behavioral and MRI changes following spinal cord trauma in minipigs.

\section{Materials and Methods}

The experimental protocols were developed in accordance with the legislation of the Slovak Republic (Animal Protection Act No. 15/1995) and approved by the State Veterinary and Food Administration in Bratislava (decision No. 2812/13-221) as well as by the Ethics Commission of the Institute of Neurobiology, Slovak Academy of Sciences in Kosice.

The preparatory phase of these experiments is not described here, since it was published in detail in a previous paper (Sulla et al. 2012).

Address for correspondence:

MVDr. Igor Šulla, Ph.D.

Department of Anatomy, Histology and Physiology

University of Veterinary Medicine and Pharmacy

Phone: +421915984691

Komenského 73, 041 81, Košice, Slovakia 
The technique of spinal cord compression trauma and assessment of neurological deficit

The SCI was performed by a computer operated apparatus with a disinfected active part (piston of stainless steel with $5 \mathrm{~mm}$ diameter) compressing the spinal cord with a peak force of $0.8 \mathrm{~kg}$ at a velocity of $3 \mathrm{~cm} \cdot \mathrm{s}^{-1}$. The action of the device was controlled by software ("FORCE", ViDiTi, Kosice, Slovakia) which enabled programming different parameters of spinal trauma. After finishing the intraspinal part of the experiment, the surgical wound was sutured and the animals were placed into disinfected compartments under controlled conditions. After recovery from anaesthesia they were offered drinking water ad libitum and a full diet. Their general health was evaluated daily by one member of our team. Detailed assessment of the motor function was carried out by two independent investigators on the $7^{\text {th }}$ and $12^{\text {th }}$ post-SCI day using the 14-point porcine neurological motor scoring system (PNM score) - based on the BBB evaluation system elaborated for rats (Basso et al. 1995) and modified for pigs (Navarro et al. 2012).

Magnetic resonance imaging and evaluation of results

On the $12^{\text {th }}$ postoperative day the minipigs were euthanasied by deep thiopental anaesthesia with a transcardial perfusion of $5000 \mathrm{ml}$ of heparinized saline and fixed by the same volume of $4 \%$ paraformaldehyde in $0.1 \mathrm{M}$ phosphate buffer at $\mathrm{pH}$ 7.4. The vertebral columns were dissected, operative sites were examined, and spinal cords removed. The extent and character of neural tissue damage was evaluated by post mortem MRI of isolated spinal cord segments immersed in Fomblin Y (Sigma-Aldrich, Bratislava, Slovakia) on 4.7 T horizontal scanner (Agilent, Yarton, Great Britain) equipped with $400 \mathrm{mT} \cdot \mathrm{m}^{-1}$ gradient insert and DDR console. Quadrature volume coil transmitter with i. d. of $72 \mathrm{~mm}$ and dual channel surface coil receiver (Rapid Biomed, Rimpar, Germany) was used for excitation and detection, respectively. T1 weighted images were obtained using gradient echo sequence $\mathrm{TR} / \mathrm{TE} / \mathrm{FA}=250 \mathrm{~ms} / 3.5 \mathrm{~ms} / 39^{\circ}$ with 180 averages giving a total acquisition time of $1.2 \mathrm{~h}$. In-plane resolution was $0.1 \mathrm{~mm} \times 0.1 \mathrm{~mm}$ and slice thickness $0.8 \mathrm{~mm}$. PD weighted images were obtained using spin echo sequence FSEMS TR/TE/ $=3000 \mathrm{~ms} / 10 \mathrm{~ms}$ with 100 averages giving a total acquisition time of $1.3 \mathrm{~h}$. No contrast material enhancement was used. The damaged area of the spinal cord depicted on the MR images was measured in pixels from the epicentre of the lesion and its proportion to the total area of gray or white matter was calculated using free software GIMP 2.8 (Image Manipulation Program). Statistical analyses were performed by Spearman's rho test for nonparametric correlations.

The spelling of Latin terms was confirmed with the Veterinary Vocabulary (Danko and Simon 2012).

\section{Results}

All 6 animals survived the experimental procedures without complications. No urinary retention, anal prolapse, or decubitus ulcers developed during the survival period. At the time of euthanasia the surgical wounds were healed per primam intentionem. The post mortem dissection of neural structures showed fibrotic adhesions between the dura mater and the underlying spinal cord at the epicentre of the injury in all minipigs.

On the $2^{\text {nd }}$ day after SCI the experimental animals were able to sit on one side and slightly move one hindlimb but not their tails and they urinated and defecated involuntarily, thus demonstrating a severe neurological deficit. However, their motor functions improved rapidly from the $2^{\text {nd }}$ to the $7^{\text {th }}$ post-SCI day: almost complete paraplegia on the $2^{\text {nd }}$ post-SCI day (Grade 1 of the PNM scoring system) to Grade 7 (2 minipigs were able to perform extensive movements in all three joints of both hindlimbs but were not able to stand up or move tails) and Grade 8 (4 minipigs were able to move tails and perform extensive movements in all three joints of both hindlimbs but were not able to bear weight even if initially helped to stand) on the $7^{\text {th }}$ post-SCI day. Further improvement occurred from the $7^{\text {th }}$ to the $12^{\text {th }}$ post-SCI day: Grade 11 (2 minipigs were able to stand up spontaneously, take several steps, inconstantly keep balance between stepping episodes, and move tails) and Grade 12 (4 minipigs were able to stand up spontaneously with sustained locomotion for at least 10 steps with frequent plantar-hoof stepping but without forelimb-hindlimb coordination) on the $12^{\text {th }}$ post-SCI day.

MR images showed loss of the spinal cord white matter (SCWM) integrity and cavitations in the epicentre of the SCI with longitudinal spreading over one segment cranially and one caudally. MR images in three minipigs revealed structural damage in the spinal cord white as well as gray matter (SCGM) and in three the lesion was restricted to gray matter (Plate VIII, Fig. 1). The extent of each damaged area (SCWM, SCGM, or both), measured in pixels from the epicentre of the SCI, is presented in Table 1 as a percentage of the total area of SCWM or SCGM in the MR image. 
Table 1. Proportion of the damaged areas of white and/or gray matter to the total white or gray matter areas of the spinal cord revealed by MR images taken from the epicentres of compression trauma on the $12^{\text {th }}$ post-SCI day.

\begin{tabular}{crccccc}
\hline $\begin{array}{c}\text { Minipig } \\
\text { No }\end{array}$ & $\begin{array}{c}\text { Total area of } \\
\text { SCWM }\end{array}$ & $\begin{array}{c}\text { Damaged area } \\
\text { of SCWM }\end{array}$ & $\begin{array}{c}\text { Proportion of } \\
\text { damaged area } \\
\text { of SCWM }\end{array}$ & $\begin{array}{c}\text { Total area of } \\
\text { SCGM }\end{array}$ & $\begin{array}{c}\text { Damaged area } \\
\text { of SCGM }\end{array}$ & $\begin{array}{c}\text { Proportion of } \\
\text { damaged SCGM }\end{array}$ \\
\hline 1 & 93078 & 1920 & 2.07 & 11518 & 75 & 0.65 \\
2 & 0 & 0 & 0 & 17925 & 1721 & 9.6 \\
3 & 96065 & 820 & 0.85 & 13813 & 1243 & 8.99 \\
4 & 0 & 0 & 0 & 13398 & 889 & 6.63 \\
5 & 0 & 0 & 0 & 9862 & 128 & 1.29 \\
6 & 79971 & 8480 & 10.6 & 8706 & 796 & 9.14 \\
\hline
\end{tabular}

SCWM - spinal cord white matter; SCGM - spinal cord gray matter; areas are quoted in pixels; proportions are quoted in $\%$

Statistical analyses revealed positive correlation between the damaged portions of SCWM and the whole areas of SCWM in the MR images from the epicentre of SCI $\left(P=0.046, r_{s}=0.742\right)$; the same positive correlation was found between the damaged portions of SCGM and the total areas of the SCGM $\left(P=0.002, \mathrm{r}_{\mathrm{s}}=0.943\right)$.

\section{Discussion}

Traumatic SCI results in an acute disruption of afferent and efferent signals and the inability to process motor, autonomic and reflex activities within the damaged part of the spinal cord (Benes 1987). The effect of SCI is considered in two stages - the primary injury (regarded irreversible) and the secondary injury (McDonald and Sadowsky 2002; Oyinbo 2011). The character of pathological processess participating in the secondary injury and the fact that their development may progress over hours, days, or even weeks, offers a chance to apply therapeutic interventions (Joshi and Fehlings 2002; Kwon et al. 2010). The most frequently used experimental animals in SCI and related studies are mice, rats and rabbits (Vanicky et al. 2001; Joshi and Fehlings 2002; Akhtar et al. 2008; Mazensky et al. 2011). Small animal models are very useful in biological research; however, they may not recapitulate adequately processes characteristic of diseases in humans (Fehlings and Baptiste 2005; Akhtar et al. 2008). On the other hand, cats, dogs, pigs or non-human primates have relatively large central nervous systems and share many anatomic and physiological characteristics with humans (Akhtar et al. 2008; Navarro et al. 2012). The technique of laminectomy in different regions of their vertebral columns is standardised (Srnec et al. 2012; Sulla et al. 2012). This makes them suitable for studies of neurological diseases, brain and spinal cord imaging, assessment of new pharmaceuticals, surgical techniques, and disease models (Akhtar et al. 2008; Kwon et al. 2010). Due to emotional reasons we did not use cats or dogs in our experiments; the utilisation of apes exceeded our financial and technical possibilities. The potential of pigs for modelling human brain and spinal cord disorders has been widely recognized (Akhtar et al. 2008; Navarro et al. 2012). In view of these features, minipigs from GoettingenMinnesota and Libechov farm strains crossbreeding appeared to us the most suitable experimental animals for the study of processes developing in the spinal cord following compression injury and subsequently for testing different therapeutic measures (Sulla et al. 2012). Such study is possible only in models with an incomplete spinal cord lesion (Joshi and Fehlings 2002; Kwon et al. 2010). The compression by 1.5 and $2.5 \mathrm{~kg}$, 
which we tested in individual minipigs during the preparatory phase before starting the actual study, produced severe contusion of the cord (Sulla et al. 2012). As a consequence, long lasting paraplegia developed (Navarro et al. 2012). This did not suit our plans, so we chose a reduced force of $0.8 \mathrm{~kg}$ for SCI in the study.

Assessment of the behavioural outcome after SCI is considered very important; we used the PNM score (Navarro et al. 2012) for this purpose.

Clinical studies in humans have shown that trying to predict the correlation between the severity of the neurological deficit and the static findings on MR images obtained shortly after the spinal trauma is not reliable since it does not take into account the dynamic character of the complicated events accompanying SCI (Potter and Saifuddin 2003). For assessing such correlations, MR images obtained 2-3 weeks later are more accurate (Shimada and Tokioka 1999). Using the 12-day survival period we tried to get as close as possible to this recommendation. Some authors consider MRI studies performed in the chronic post-SCI stage also useful (Potter and Saifuddin 2003). Technical parameters of the MR apparatus, designed for mice and rats, enabled only examinations of fixed (ex vivo) specimens of spinal cords. The limited number of minipigs did not allow us to create an acute and a chronic subgroup.

Fomblin Y (perfluoropolyether vacuum oil) is biologically and chemically inert oil, which resists water and is insoluble in most organic solvents. This special oily substance was used during MR examinations for immersion of spinal cord specimens with the aim of reducing background signals and susceptibility artifacts.

In conclusion, our study confirmed the reliability and reproducibility of this SCI experimental model. The behavioural and MR characteristics in minipigs were similar to the consequences of this type of trauma in humans. The model may help to study new therapeutic approaches targeted to modulate neuropathological processes in different phases of this clinical entity.

\section{Acknowledgements}

The authors would like to express their gratitude to Giorgi Mgebrishvili from the Department of Clinical and Molecular Pathology, Palacky University, School of Medicine, Olomouc, Czech Republic for statistical analyses and to W. Bradford DeLong, MD from the Department of Neurosurgery, University of California, San Francisco, USA for English language proofreading. The study was supported by the grant of the Agency of the Ministry of Education, Science, Research and Sport of the Slovak Republic for the Structural Funds of EU, ITMS 26220220127.

\section{References}

Akhtar AZ, Pippin JJ, Sandusky CB 2008: Animal models in spinal cord injury: a review. Rev Neurosci 19: 47-60 Animal Protection Act of the Slovak Republic No 15/1995 (in Slovak), part 39, p. 1250-1255

Basso, MD, Beattie MS, Bresnahan JC 1995: A sensitive and reliable locomotor rating scale for open field testing rats. J Neurotrauma 12: 1-21

Benes V 1987: Spinal Cord Injuries (in Czech), $3^{\text {rd }}$ edition, Avicenum, Praha, 189 p.

Danko J, Simon F (Eds) 2012: Veterinary Vocabulary (in Slovak). Ikar, Bratislava, 416 p.

Fehlings MG, Baptiste DC 2005: Current status of clinical trials for acute spinal cord injury. Injury 36 (Suppl): $113-122$

Joshi M, Fehlings MG 2002: Development and characterization of a novel, graded model of clip compressive spinal cord injury in the mouse: Part 2. Quantitative neuroanatomical assessment and analysis of the relationships between axonal tracts, residual tissue, and locomotor recovery. J Neurotrauma 19: 191-203

Kwon BK, Hillyer J, Tetzlaff W 2010: Translational research in spinal cord injury: a survey of opinion from the SCI community. J Neurotrauma 27: 21-33

Mazensky D, Petrovova E, Luptakova L 2011: Anatomical study of blood supply to the spinal cord in the rabbit. Spinal cord 49: 525-528

McDonald JW, Sadowsky C 2002: Spinal-cord injury. Lancet 359: 417-425

Navarro, R, Juhas S, Keshavarzi S, Juhasova J, Motlik J, Johe K, Marsala S, Scadeng M, Lazar P, Tomori Z, Schulteis G, Beattie M, Ciacci JD, Marsala M 2012: Chronic spinal compression model in minipigs: A systematic behavioral, qualitative, and quantitative neuropathological study. J Neurotrauma 29: 499-513 
Oyinbo CA 2011: Secondary injury mechanisms in traumatic spinal cord injury: a nugget of this multiply cascade. Acta Neurobiol Exp 71: 281-299

Potter K, Saifuddin A 2003: MRI of chronic spinal cord injury. Br J Radiol 76: 347-352

Shimada K, Tokioka T 1999: Sequential MR studies of cervical cord injury: Correlation with neurological damage. Spinal Cord 37: 410-415

Srnec R, Proks P, Fedorova P, Stehlik L, Dvorak M, Necas A 2012: Myelographic diagnosis and results of surgical treatment of caudal cervical spondylomyelopathy in dogs: a restrospective study (2000-2010). Acta Vet Brno 81: $415-420$

Sulla I, Boldizar M, Racekova E, Balik V 2012: Thoracic laminectomy technique in minipigs. Folia Vet 56: 35-39

Vanicky I, Urdzikova L, Saganova K, Cizkova D, Galik, J 2001: A simple and reproducible model of spinal cord injury induced by epidural balloon inflation in the rat. J Neurotrauma 18: 1399-1407 


\section{Plate VIII}

Šulla I. et al.: Assessment.. pp. 393-397
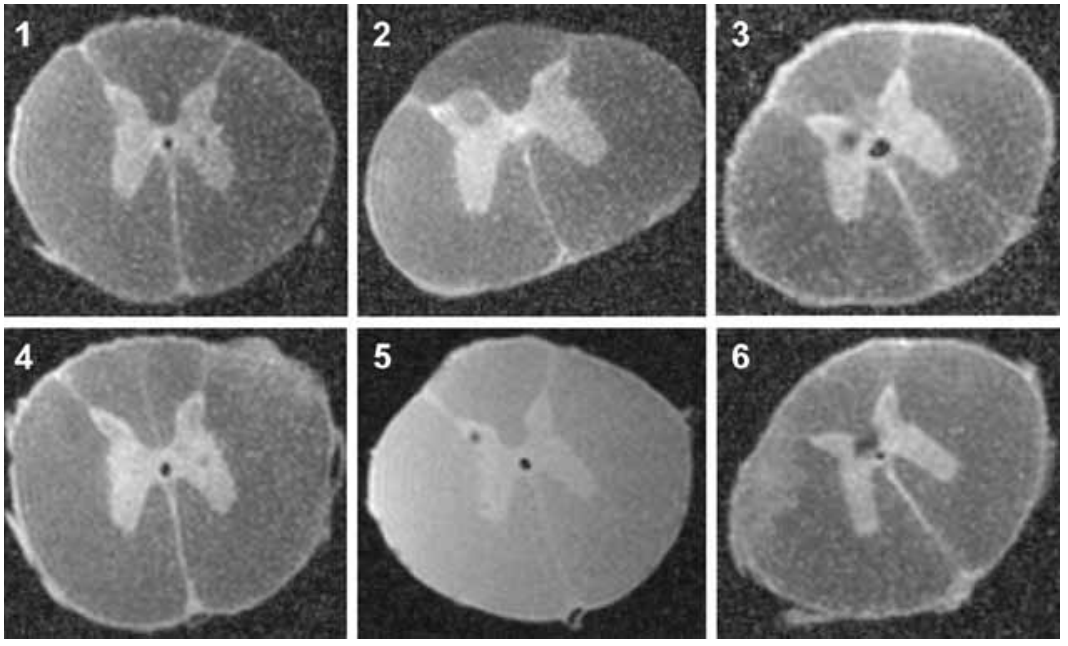

Fig. 1. MR images (marked by the number of the minipig) of spinal cord segments located in the epicentre of compression 12 days after SCI 